\title{
De novo AVM formation
}

\author{
Brandon A. Miller • David I. Bass • Joshua J. Chern
}

Received: 5 January 2015 / Accepted: 4 February 2015 /Published online: 17 February 2015

(C) Springer-Verlag Berlin Heidelberg 2015

Dear Editor:

We read with great interest the recent report by Yeo and colleagues [2] describing two cases of de novo AVMs in children. Their cases and literature review provide further evidence that AVMs, especially in children, are dynamic lesions that can appear and change throughout a patient's lifetime. Our recent publication [1], which was not included in their review, provides another case example of de novo formation of a pediatric AVM. Like the majority of patients described in their review, our patient had a history of a possible inciting event (a severe traumatic brain injury) that may have contributed to formation of the AVM. Additionally, the patient we described presented with seizures, as did one of the patients described by Yeo and colleagues. This reinforces the fact that new neurologic symptoms must be investigated with appropriate studies even in patients who have previously undergone neuroimaging.

\section{References}

1. Miller BA, Bass DI, Chern JJ (2014) Development of a de novo arteriovenous malformation after severe traumatic brain injury. $\mathrm{J}$ Neurosurg Pediatr 14:418-420

2. Yeo JY, Low SYY, Seow WT, Low DCY (2014) Pediatric de novo cerebral AVM: report of two cases and review of literature. Child's Nervous System published online December 24, 2014

B. A. Miller $(\triangle) \cdot$ D. I. Bass $\cdot$ J. J. Chern

Department of Neurosurgery, School of Medicine, Emory University, 1365-B Clifton Road, Suite 6200, Atlanta, GA 30322, USA

e-mail: brandon.miller@emory.edu

\section{J. J. Chern}

Children's Healthcare of Atlanta, Atlanta, GA, USA 